\title{
THE 1981 ERUPTIVE FISSURE ON MT. ETNA: CONSIDERATIONS ON ITS EXPLORATION AND GENESIS
}

\author{
Angelo Leotta * and Marco Liuzzo *
}

\begin{abstract}
This paper is targeted to an analysis of features common to various fissure caves on Mt. Etna, Sicily. The Authors report the preliminary results of the exploration carried out in the 1981 eruptive fissure, the technical problems met during the exploration, the flow trends and the different courses of the molten material inside the fissure, the particular morphologies. A genetic model is proposed, different from those characterising the lava tube cave genesis, and links are suggested between the various fissures and the main tectonic stress systems operating on Mt. Etna, as well as the morpho-structural conditions of the volcanic edifice of Mt. Etna.
\end{abstract}

Keywords: speleogenesis; eruptive fissure; Mt. Etna, Italy

\section{FOREWORD}

The eruptive fissures of Mt. Etna have been carefully and systematically investigated in the last decade. Starting from a limited knowledge of the upper segment of some fissures, this study brought to a list of eight fissure caves completely surveyed (table 1):

\begin{tabular}{|c|l|c|c|}
\hline N & \multicolumn{1}{|c|}{ NAME OF THE CAVE(S) } & $\begin{array}{c}\text { ERUPTION } \\
\text { YEAR }\end{array}$ & $\begin{array}{c}\text { INVOLVED } \\
\text { FLANK }\end{array}$ \\
\hline 1 & Abisso di PROFONDO-NERO (Deep-Black Abyss) & 1923 & North-East \\
\hline 2 & Abisso del GHIACCIO (Ice Abyss) & 1947 & North-East \\
\hline 3 & Buca della MARINITE (Marinite Hole) & 1928 & East \\
\hline 4 & Grotta delle PALOMBE (Doves Cave) & 1669 & South-East \\
\hline 5 & Grotta MARASCA (Marasca Cave) & 1986 & East \\
\hline 6 & Grotte di SERRACOZZO I-II (Serracozzo I-II Caves) & 1971 & East \\
\hline 7 & Bocche Eruttive di Ripa della Naca (Eruptive Vents at Ripa della Naca) & 1928 & East \\
\hline 8 & Fratture del 1981 (1981 Eruptive Fissures) & 1981 & North \\
\hline
\end{tabular}

Some cavities, e.g. the Palombe, the Serracozzo, the Marasca and the Marinite caves, are partially fissure and partially lava tube caves; other caves, e.g. the 1780 fissure cave, have been sealed by subsequent eruptions and cannot be further investigated. The first two caves in the list resulted more than $100 \mathrm{~m}$ deep, with several hundreds of meters length, whereas our survey ascertained much smaller dimensions in the remainder caves.

It must be also considered that each lateral eruption outcrops from a fissure opened in the volcano flanks, which means that much more fissure caves than the known ones are potentially existing on Mt. Etna, although several fissures are actually inaccessible.

\footnotetext{
* Centro Speleologico Etneo 4CSE), Via Cagliari, 15 - 95127 CATANIA, Italy.
} 


\section{GEOLOGIC PATTERNS}

Mt. Etna rises to more than $3300 \mathrm{~m}$ North of the Plain of Catania, in the western Mediterranean area; it is the highest active volcano in Europe. The first volcanic evidences date back to 500.000 years ago: traces of submarine intrusions have been ascertained at Acicastello (Romano, 1982), a coastal village close to Catania. During the subsequent phases of the volcanic activity, the volcanic axes migrated from the SE sea bottom to NW, shifting from submarine to subaerial conditions, up to the present position.

Mt. Etna presently produces a generally basic magmatism, featured by low viscosity lava, which in turn facilitates the lava cave formation, witnessed by over 200 caves known and surveyed on the volcano (AA. VV., 1994).

The classic volcanology outlines two main kinds of eruption: the summit eruptions and the lateral ones. The first type outpours from the central eruptive apparatuses of the volcano. The central eruptions on Mt. Etna did not generate significant caves from a speleological point of view, due to several reasons; Mt. Etnas eruptive style and prevailing morphology are worth consideration among them.

The latter type, i.e. the lateral eruptions, can outpour from whichever side of the volcano, at whichever height, through a breach in the surface crust. Such a gap allows the magma to raise toward the surface, forming one or more ephemeral cones, wherefrom explosive and effusive products are thrown all around. The molten lava effusions govern the formation of the well known lava tube caves, whereas the eruptive fissures and the related overlying cones (through which the access to the hollow could be possible) support the genesis of the fissure caves (fig. 1).

The magma flows inside the fissure by a composite motion, which can be temporally altered, since the local surfacial topography governs vertical mouvements (upward and downward) and lateral downflows. The fissure is first invaded by gases, which open the preexisting weakness planes by their high temperature and pressure, and prepare the path for the hot molten material. Gases themselves govern the upward magma motion: the deep magma chambers hold the gases completely dissolved in the molten body, and volcanologists name "hypomagma" this phase. The opening of the fissure generates a reduction in the hydrostatic pressure affecting the magma; this in turn induces a segregation of the gases into bubbles exerting their own internal pressure, and this latter phase is named "pyromagma" by volcanologists. Due to their reduced density in comparison with the molten material, the bubbles trend upward, and their velocity is directly proportional to the square of their radius and inversely proportional to the viscosity of the molten stuff (Stokes Law). The loss of hydrostatic pressure causes an adiabatic dilatation of the bubbles, which increase their ascensional velocity and share their motion with the engulfing fluid.

When a bubble reaches the surface, the gases explode and can throw molten spatters even at a distance of hundreds of meters (Rittmann, 1967). The spatters falling around the fissure build up welded spatter cones named hornitos, often aligned with the direction of the fissure (Fig. 2), whereas the effusive vent, named oven mouth, is placed at the lower end of the fissure. The environment beyond the oven mouth is wider and no more saturated by magma, and lava can freely degas to the air. This passage couples the one from phreatic into vadose or subaerial circulation in a carstic environment. In other words the magma comes to surface under gases push, and outpours from the lower end of the fissure. This determines a fluids lateral motion, to be added to the previously described vertical motion. Yet magma rate of discharge vary continuously during the eruption, and this governs in turn a downward variable motion inside the fissure.

The resulting motion of magma inside the fissure, governed by the named factors, 


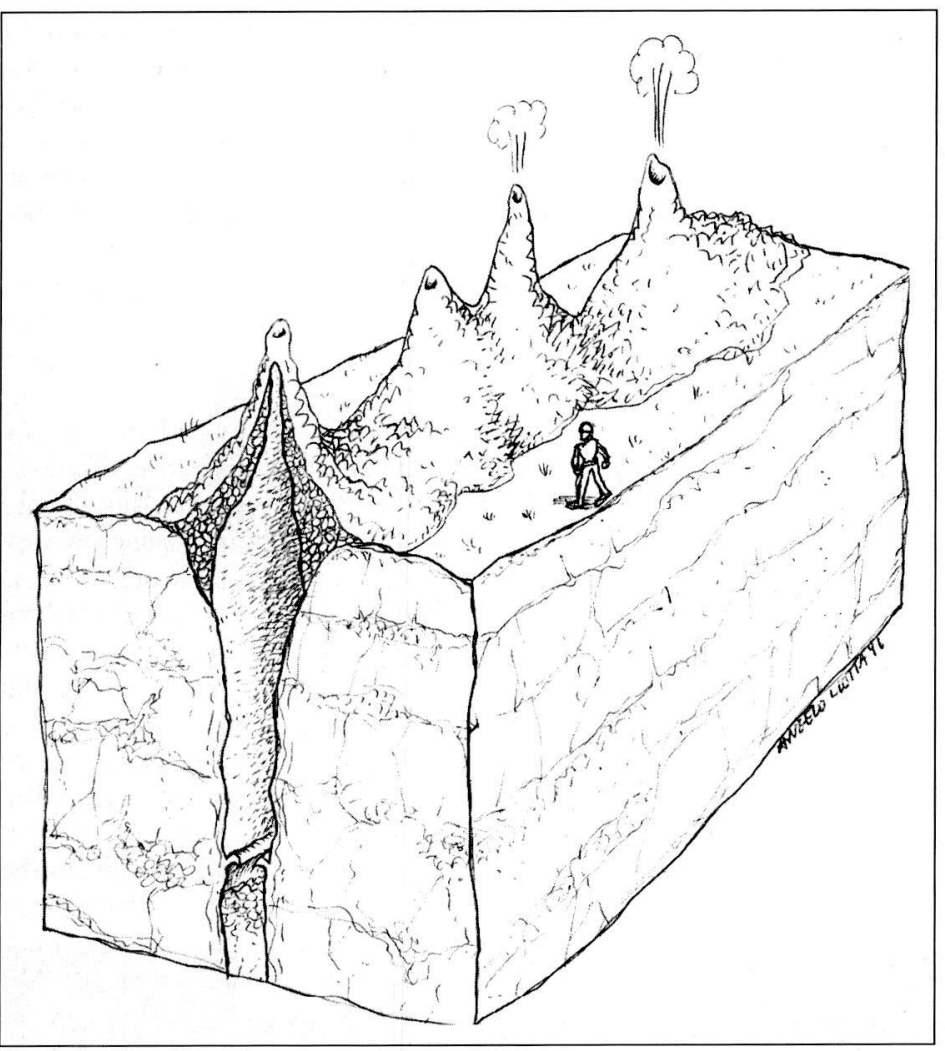

Fig. 1 - Ipotetic tridimensional sketch with hornitos, fissure and, inside, small horizontal shelves.

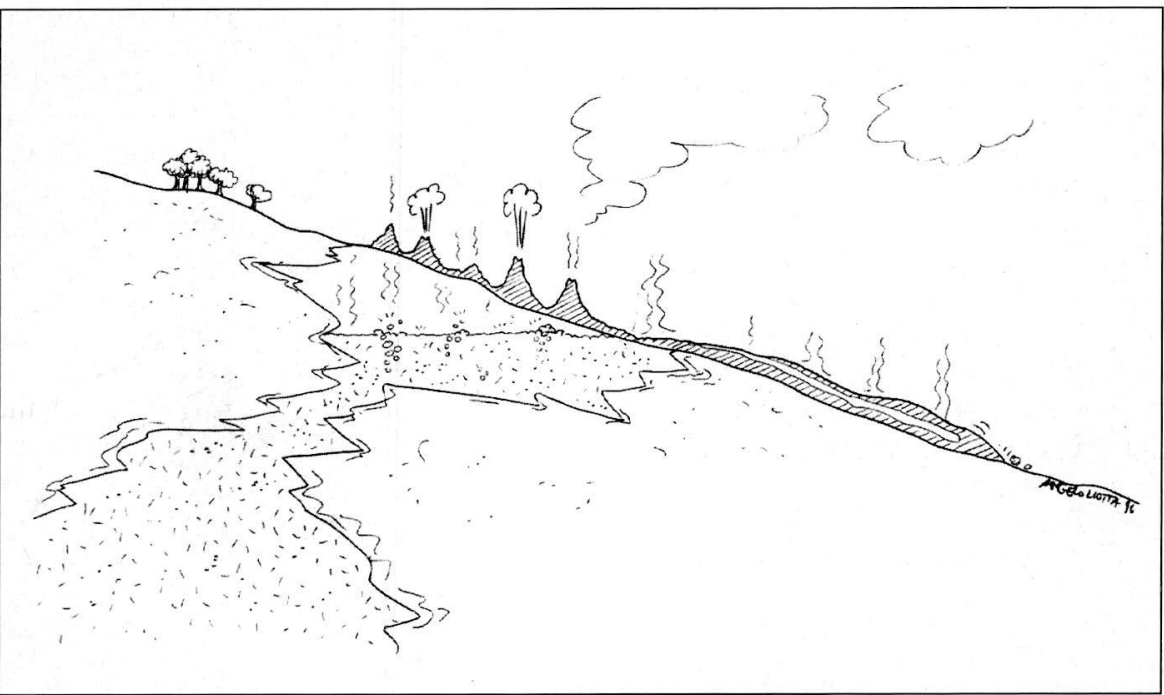

Fig. 2 - Hornitos aligned with the direction of the fissure: at the lower end is placed the effusive vents, named "oven mouth". 
should involve a slantwise trend, though no witness can be found, since a diminution of the upward push results into a fall down of the discharge rate and this induces in turn a downward vertical motion of the fluid inside the fissure, up to the end of the eruption. Any possible slanting trace produced on the still plastic walls of the fissure, is only a relic, generally effaced by the most usual vertical groves produced by the last motion (Fig. 3). The decreased flow rate induces the formation of a hollow in the upper part of the fissure, which can be eventually explored by the speleologists (Fig. 4).

\section{GENETIC MODEL AND CAVES MORPHOLOGY}

According to Anderson and Grews theory (stress corrosion cracking theory, 1977), the ascending magma exerts an excess of pressure on the lithostatic load in the area close to the surface, and this generates an upward trending gap. No preexisting fissure is required for implementing this mechanism. Yet some weakness trends, generated by the regional tectonics, could supply a path to the ascending magma. A pressure increase inside the magma chamber allows the gases to segregate from the fluid and start an upward push by widening a preexisting fissure, or opening a new one in a weaker area. Then the gases squeeze themselves inside the fissure, and implement an additional widening by corrosion. At this stage the molten material, pushed upward by the gases, bursts into the gap and breaks out the actual path of the effusion toward the surface.

The first batch of the fluid becomes immediately chilled for the abrupt thermal fall in the contact area with the engulfing rocks. Thus a non-conducting pad prevents further heath losses during the fluids upward motion. The chilling of the fluid inside the

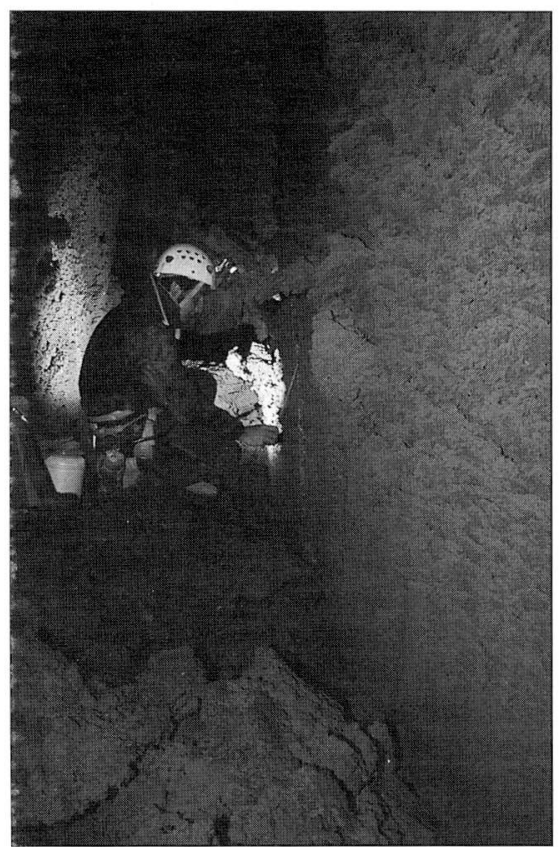

Fig. 3 - Trace produced by the last motion.

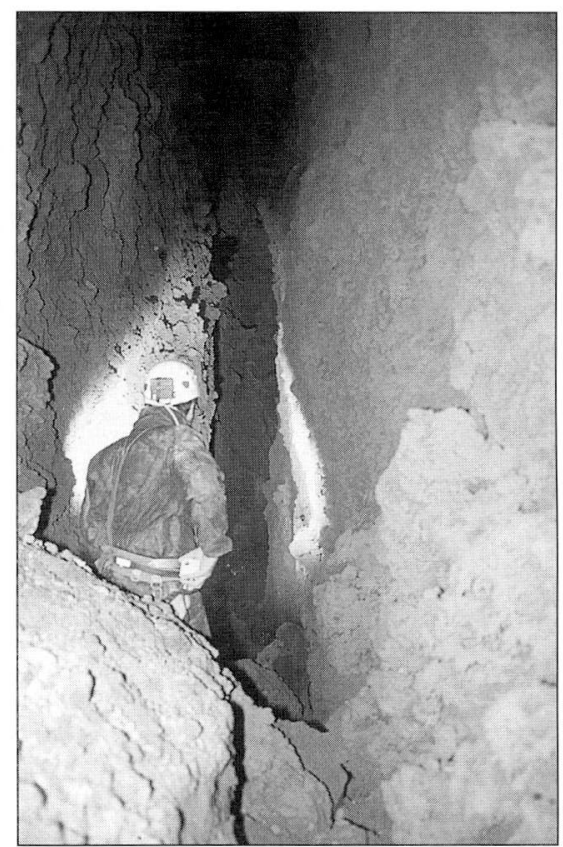

Fig. 4 - The upper part of the fissure which can be explored. 
fissure is centripetal: therefore subsequent concentric plaster layers are formed, starting from the fissure inner surface.

A remarkable feature observed inside the eruptive fissures is that they consist of a train of hollows spaced by intermediate oven mouths, rather than a single vertical hollow. A parallelism can be suggested, between the outer ephemeral vents and the inner oven mouths, according to the age and the position of the fissure, by observing the external morphology of the lava flows. The eruptive fissures are therefore extremely jointed hollows which develop downward through a train of levels increasingly deep spaced by inner oven mouths; these latter are distributed according to a kind of regressive migration, with an increasingly low level inside the fissure, from the outermost mouth downslope to the increasingly innermost ones, whose height is topographically lower.

The hollow inside the examined fissure has not a linear trend: the inner waveshaped surfaces governed the magmatic flow influencing local slackenings and chillings and final obstructions contrasting the linear magmas path. The recurrent ups and downs in the inner course of the fissure witnesses this mechanism: small rooms generated by collapsed walls, showing the engulfing rocks (Fig. 5), are often followed by climbs along obstruction by chilled magma.

The walls also display horizontal wrinkles due to the temporary magma standings, whereas some vertical strias have been supposed to be the result of an alternance between standing and subsequent reduction in magmas discharge rate. This governs the formation of small horizontal shelves as the still plastic wall, missing the support of its filling, slips downward and folds prior to its final chilling (Fig. 6); in the meantime more viscous or solid parts of the lowering fluid carve vertical grooves into the walls. Somewhere else a new surge and subsequent re-lowering of the lava filling can be supposed to have determined a flattening of the observed horizontal shelves with vertical strias.

The horizontal shelves at small intervals (about one meter) could witness a remarkable periodical alternance of standings and lowering of the fluid filling (Fig. 7). This probable periodicity is surely implemented by some unknown mechanism of the magma chamber.

The trend of the shelves in some segments of the cave follow the ups and downs commanded by the local topography, though they remain essentially parallel one another. Lateral rolls can also be observed along the lower gallery, similar to those found in the lava tube caves and most likely generated by the same mechanism: during its activity the fluid deposits layers of plaster on the fissure walls, which are affected by centripetal chilling. An abrupt reduction in the rate of discharge, and the consequent lowering of the filling, deprive the inner layer of a valid support, thus probably implementing its curling down and reaching the final roll shape.

\section{ERUPTIVE FISSURES AND REGIONAL TECTONICS}

A basic question is whether we can correlate the lateral eruptions with the main tectonic trends of Mt. Etnas edifice, which in turn are related with the regional tectonics. If we can affirm that a fissure in the rock is the reply to an external stress, we can even try and understand the relationship between the examined caves' and the tensional system ruling the eastern side of Sicily. A mere check of the direction of the surveyed fissures, for example, shows that the Profondo-nero abyss, the Marasca cave, the Marinite hole and the caves at Ripa della Naca display a uniform ENE-WSW trend; this trend, limited to some selected areas of the volcano, follows the main fault system named "Acate-Caltagirone-Ponte Barca system" (Ghisetti \& Vezzani, 1981) and "Messina-Fiumefreddo 


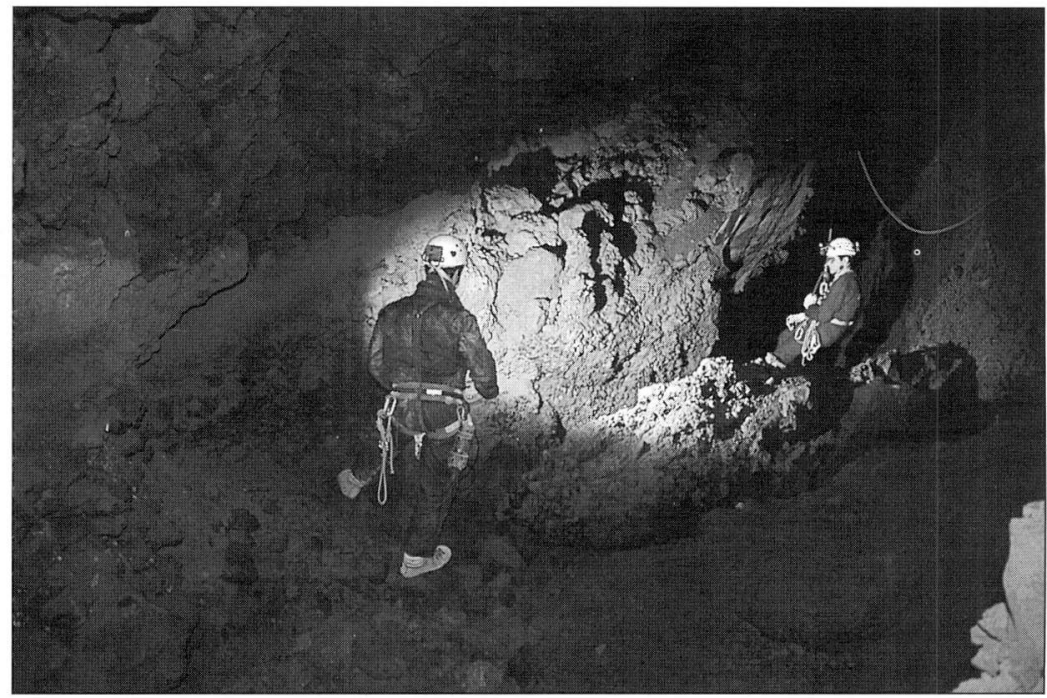

Fig. 5 - Small room generated by collapsed walls.

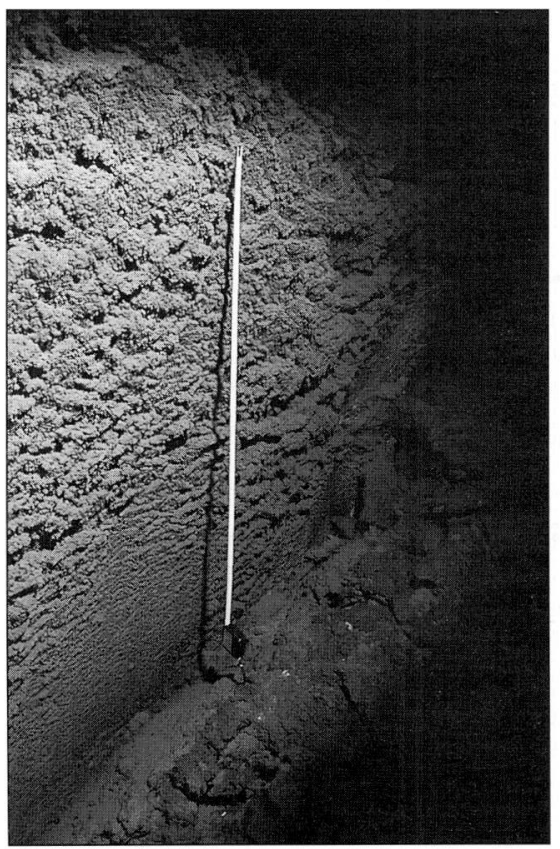

Fig. 6 - Horizontal trace due to the temporary magma standings.

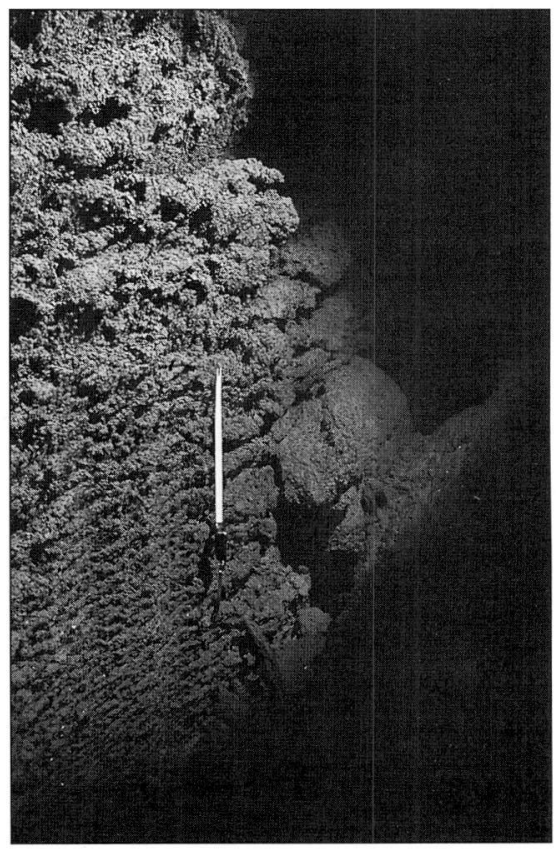

Fig. 7 - Horizontal shelves: periodical alternance of magma standings. 
system" (Ghisetti, 1979) by the geologists, the Ice abyss is NNE-SSW oriented, just like the Central Chasm and the NE Crater of Mt. Etna, whereas the Doves Cave trend is aligned NNW-SSE, in accordance with the Ibleo-Maltese scarp.

In other words, a lava tube cave can display whichever trend, somehow governed only by the preexisting topography, whereas the orientation of the eruptive fissures are most likely linked with regional tectonic phenomena, which govern and implement their opening. This in turn can explain why a fissure genesis is not directly implemented by the magma surge, but is governed by multiple interacting factors.

\section{CONCLUSIONS}

Fissure caves display several differences, though they share many features with the lava tube caves: these latter are usually built up on the preexisting ground, whereas the former ones usually lay at a lower level, entirely contained by the engulfing rock. Tectonic stresses must be considered a basic factor in their genesis, as they implement the weakness trends through which the increased pressure pushes gases and fluid material.

Magmas motion inside the fissure is influenced by heavy changes in the discharge rate (abrupt downflows, etc.), which implement a regressive shift of the oven mouths, and by light changes, witnessed by small wall shelves featured by some periodicity.

The correspondence between the main tectonic trends of the Mt. Etna region and the orientation of the observed fissures is evident. Yet we deem that the quantity of acquired data doesn't yet account for a firm correlation between the two phenomena. In any case we suppose that the field evidences supply some hints worth of consideration, to be investigated and compared with similar situations in other volcanic areas.

Fissure surveys are not as affordable as other cave surveys, since they require specific technical cautions which cannot be arranged on the spot. Yet we deem that their investigation and study is worth a steady commitment which can solve many questions and can supply many and very interesting data.

\section{ACKNOWLEDGMENTS}

The authors are indebted to their fellow Giuseppe Maria Licitra for his determinant support in the translation of this paper into English, and Angelo Liotta for his precious and clear pictures. They also gratefully acknowledge Centro Speleologico Etneo financial support for the fulfilment of their work.

\section{REFERENCES}

AA.VV., 1994. Atti del II Congresso Regionale di Speleologia, Catania 8-11 Novembre 1994.Boll.Accad.Gioenia Sci. Nat., Vol. 27, N. 348 Catania 1994.

ANDERSON, O. L. \& GREW, P.C., 1977. Stress corrosion theory of crack propagation with applications to geophysics. Rev. Geophys. Space Phys., 15, 77-104.

GHISETTI, F. 1979. Evoluzione neotettonica dei principali sistemi di faglie della Calabria centrale. Boll. Soc. Geol. It., 98, 387-430.

GHISETTI, F. \& VEZZANI, L. 1981. Contribution of structural analysis to understanding the geodynamic evolution of the Calabrian arc (Southern Italy). Journal Struct. Geol., 3, 371-381.

RITTMANN, A. 1967. I vulcani e la loro attività. Cappelli Editore, 1967.

ROMANO, R. 1982. Succession of the volcanic activity in the etnean area. Mem. Soc. Geol. Ital., 23, 27-48. 